\title{
SOCIAL REPORTING AND NEW GOVERNANCE REGULATION: THE PROSPECTS OF ACHIEVING CORPORATE ACCOUNTABILITY THROUGH TRANSPARENCY
}

\section{David Hess}

\begin{abstract}
This paper argues that social reporting can be an important form of New Governance regulation to achieve stakeholder accountability. Current social reporting practices, however, fall short of achieving stakeholder accountability and actually may work against it. By examining the success and failures of other transparency programs in the United States, we can identify key factors for ensuring the success of social reporting over the long term. These factors include increasing the benefits-to-costs ratios of both the users of the information and the disclosers, and recognizing the importance of the involvement of third-party intermediaries.
\end{abstract}

$\mathrm{T}$ here is a significant and growing interest in the legal academy in exploring new ways to regulate corporations and, in particular, an interest in a shift from regulation to governance. Conventional models, such as command-and-control regulation, operate under a deterrence approach to regulation (Malloy 2003), which is generally adversarial and punitive (Ruhnka and Boerstler 1998). Although this traditional approach to regulation has provided many benefits to society (e.g., cleaner air, safer products, and less discrimination), it has its limits and in some cases may have the unintended consequence of actually reducing social welfare (Aalders and Wilthagen 1997; Sunstein 1990). For example, some argue that a strict and inflexible regulatory approach may cause some organizations to adopt an adversarial approach to regulators, instead of making good faith attempts to follow the law (Malloy 2003).

In response to the need for the law to evolve to reflect changes in society and growing complexities, governments have experimented with new approaches to regulation that come closer to self-regulation. ${ }^{1}$ Although critics view self-regulation as simply advancing a policy of deregulation (Sinclair 1997), an increasing number of legal scholars reject a choice between self-regulation and command-and-control and advocate a legal regime based on governance. This "New Governance" model of regulation replaces centralized regulation with a more collaborative approach and works from the belief that "economic efficiency and democratic legitimacy can be mutually reinforcing” (Lobel 2004: 344). 
The growing interest in corporate environmental and social reporting (referred to here simply as social reporting) for achieving corporate accountability is in step with the New Governance model of regulation. Supporters of social reporting consider it a necessary mechanism in enabling stakeholder democracy in corporate governance, which is consistent with the collaborative, participatory, and decentralized approach of New Governance regulation. These proponents argue that organizational transparency through social reporting is the key to meaningful stakeholder engagement. Often, stakeholder engagement is viewed as necessary to develop a social report, as opposed to social reporting being an enabling device for engagement. Extant practices, however, suggest that social reporting is not meeting the goals of corporate accountability through either transparency or engagement, and actually may be working against them.

This paper considers the prospects of social reporting as a New Governance form of regulation. By reviewing the experience from other transparency programs used in the United States, we can assess the prospects for social reporting to succeed politically and develop an understanding of what is needed for it to be an effective form of regulation for corporate accountability. This paper proceeds by providing a brief description of the principles of New Governance regulation in section I, followed by an assessment of current social reporting practices in the next section. Section III considers the prospects of mandating social reporting legislation and reviews the United States' experience with other transparency policies. The lessons from other transparency programs are then applied to social reports in section IV. Finally, section V provides concluding comments.

\section{The New Governance Model: From Regulation to Governance}

The New Governance model of regulation does not come from a single sociolegal theory but is a convergence of a variety of theories (Lobel 2004; Karkkainen 2004). For example, "reflexive law" is based primarily on Niklas Luhmann's theory of social systems and has been applied to such areas as environmental regulation (Orts 1995a; 1995b), workplace safety (Rogowski and Wilthagen 1994), and corporate social responsibility (Hess 1999, 2001). "Democratic experimentalism" (or "directly deliberative polyarchy"), on the other hand, finds its roots in pragmatism (Dorf and Sabel 1998) and has been applied to such areas as the environment (Karkkainen, Fung, and Sabel 2000) and employment discrimination (Sturm 2001; Garrett and Liebman 2004). Even though these two theories may be in conflict in some ways (Karkkainen 2004), they have significant commonalities and form two of the core examples of the growing New Governance paradigm. Some examples of other developments in this area include "responsive regulation" (Ayres and Braithwaite 1992), "collaborative governance" (Freeman 1997), "empowered participatory governance" (Fung and Wright 2003), and "meta-regulation" (Parker 2002).

In an attempt to understand an emerging consensus on New Governance models, Lobel (2004) identifies their basic, shared principles. In brief, New Governance 
can be described as process-oriented, flexible, participatory, and experimental. As a regulatory system, New Governance operates not by setting strict standards on regulated entities, but by setting the boundaries that allow experimentation to occur at a more local level and then allowing the lessons from those experiences to update standards and possibly be transferred to other areas. This often includes "rolling best-practices rulemaking" (Dorf and Sabel 1998: 350) or a ratcheting process, where the minimum acceptable standard continually rises based on past learning. This process is participatory in that it has a role for all sectors of society (state, market, and civil) in developing and enforcing regulation (which often cuts across different policy domains), and is based more on an ongoing partnership rather than policing (Lobel 2004; see also May 2004). This participatory approach seeks to support and enhance democratic engagement and make the policy process dynamic.

Social reporting fits into the New Governance model through its emphasis on supporting stakeholder democracy and accountability. As a governance mechanism, social reporting has two goals: organizational transparency (the "right to know") and stakeholder engagement. For example, the leading standard on social reporting, the Global Reporting Initiative's Sustainability Reporting Guidelines, state, "A primary goal of reporting is to contribute to an ongoing stakeholder dialogue. Reports alone provide little value if they fail to inform stakeholders or support a dialogue that influences the decisions and behavior of both the reporting organization and its stakeholders" (Global Reporting Initiative 2002: 9). By providing stakeholders with the information they demand, it is argued, these groups will become empowered and will hold corporations accountable for their actions. Also consistent with New Governance, accountability can occur in a decentralized manner. For example, with information on the toxic releases of local manufacturing plants, stakeholders can pressure and negotiate with those plants to develop practices that best meet the priorities of that particular community (Gunningham, Kagan, and Thornton 2004).

\section{An Assessment of Current Social Reporting Practices}

The current voluntary system of social reporting has failed to achieve either the goal of organizational transparency or stakeholder engagement. Instead, a fair assessment is that corporations have been able to co-opt a process designed for stakeholder accountability and turn it into a process of stakeholder management (Owen et al. 2000). Instead of transparency, firms have been able to engage in strategic disclosure designed to protect their legitimacy rather than paint a complete picture of the firm's social performance. Although most studies on non-financial reporting have only looked at environmental disclosures (often through annual reports and communications other than standalone reports [see Berthelot, Cormier, and Magnan 2003 for a review]), a growing consensus is that firms are only disclosing social and environmental information when they are faced with some type of crisis that threatens their legitimacy (see, e.g., Deegan 2002; O'Donovan 2002). The information disclosed, however, is designed to repair lost legitimacy and therefore 
almost exclusively emphasizes only the positive aspects of the firm's performance (Deegan 2002; Walden and Schwartz 1997; Deegan and Rankin 1996; for a review see Hess and Dunfee 2007). Most recently, Adams (2004) compared the social reports of a large, multinational chemical corporation filed in 1993 and 2000 with information on the company's social performance that she obtained through public sources, such as the news media. With respect to the company's social reports, Adams states, "The reports portray the company as one that is doing well, trying hard, and seeking to do better" (Adams 2004: 749). After comparing the social reports to the external information, however, Adams concludes, "There is little coverage of negative impacts, insufficient evidence that [the company] accepts its ethical, social, and environmental responsibilities, an arguably one-sided view of sustainability issues facing the company and a lack of completeness" (Adams 2004: 749). These studies and others strongly suggest that the apparent goal of social disclosure for most firms is to build or repair their reputation through impression management (see Hooghiemstra 2000).

The achievement of transparency-for the limited number of corporations that do file a social report-is further hindered by the lack of verification. Current verification practices do little to ensure the accuracy and completeness of information for external accountability, but may be useful for the internal use of firms to better identify risks and manage stakeholders (Ball, Owen, and Gray 2000). Some commentators suggest that current verification practices are not just ineffective, but may even be part of "a deliberate attempt to mislead society" (Gray 2001: 13). Overall, current research suggests that the strategic disclosure of information that leads to incomplete and misleading social reports is the norm for corporations.

The process of stakeholder engagement-where corporations and their stakeholders undertake a dialogue on appropriate firm behavior-also has been co-opted by business for use as a stakeholder management tool. As indicated earlier in reference to the Global Reporting Initiative, many consider engagement a central component of social reporting. Based on their review of leading standards in social reporting, Owen, Swift, and Hunt (2001: 267) state that "Stakeholder engagement is rapidly becoming an essential prerequisite for successful pursuit of the process."

Firms have experimented with a variety of stakeholder engagement practices including questionnaires, focus groups, Internet-based forums, and interviews with stakeholders or their representatives. At best, the design and intended use of most engagement practices by firms can be characterized as "informing" or "consulting," which typically involves a one-way flow of information (from the stakeholder to the firm) with no obligation on the part of the firm to act upon the information, and no power with the stakeholders to affect decision making (Cumming 2001). This is a form of "soft accountability" which does not promote participatory governance (Swift 2001). In addition, participation is limited because the corporation selects whom it chooses to hear from (Parker 2002).

At worst, stakeholder engagement can be characterized as the manipulation of stakeholders (Owen, Swift, and Hunt 2001). There is a growing consensus that a 
"managerial turn" in social reporting is turning stakeholder engagement practices into a process for stakeholder management and reputation building (Owen et al. 2000; Owen, Swift, and Hunt 2001; Swift 2001). Parker (2002: 157) concludes that current practices "are generally aimed at consulting with stakeholders in order to analyse their perspectives so that the company can decide what to do to manage the risk that stakeholder action might harm the company, rather than engaging with their concerns and opening the corporation up to democratic accountability." Owen et al. (2000) argue that this can occur because there is not a mechanism in place that creates any real type of stakeholder participation in corporate governance.

As indicated by this brief review, current social reporting practices not only may fail to achieve their intended goal of accountability, but also may work to reduce accountability. This is similar to the "paradox of compliance" problem identified by Laufer (1999) in his critique of corporate compliance programs. Laufer argues that because the Federal Sentencing Guidelines provide companies with reduced sentences for criminal violations if they have a compliance program in place (and, more important, prosecutors are less likely to even file charges), a moral hazard problem results. Firms adopt compliance programs as insurance against prosecution; but because the effectiveness of a program is difficult to determine, a firm can simply adopt the appearance of a program and actually take less care to prevent wrongdoing. The end result is more wrongful behavior. Likewise, the adoption of social reporting practices with stakeholder engagement can create the appearance of accountability. If the reporting process has no impact on firm behavior (except for use in stakeholder management), however, then firms can actually be even less accountable to their stakeholders than before. Even if social reporting is neutral with respect to achieving accountability, it is still problematic if it diverts attention away from potentially more effective means of accountability (Owen, Swift, and Hunt 2001).

\section{Future Prospects for Social Reporting: Lessons from the United States' Experience with Transparency Policies}

The number of firms issuing social reports has been continually increasing over the past several years; however, the evidence just reviewed suggests that it is not due to increased pressure on firms to be accountable but due to its success as a risk management tool. Current social reporting practices appear to be used by firms as a "legitimating tool and insurance policy" (Adams 2004: 749) that attempts to change "perceptions without changing facts" (Parker 2002: 165), which is far from the ideals of corporate accountability or use as a New Governance regulatory measure. An optimist would note that improvements in social reporting practices are occurring and that we are only in the first stages of development. Critics, however, conclude that corporations will never voluntarily disclose information that will hold them accountable (see, e.g., Adams 2004; Walden and Schwartz 1997). For example, Gray (2001: 14) states the general principle that, "If an organisation does 
voluntarily produce social accounts, they are probably, by definition, not going to advance accountability, and by corollary, only if the organisation does not want to produce the information is it likely to benefit society." Because of these problems, some suggest that social reporting will become a disappearing management fad or a public relations tool unless we address the issue of stakeholder power and somehow institutionalize stakeholder participation in governance (Owen et al. 2000; Owen, Swift, and Hunt 2001).

This section takes a look at the prospects of making social reporting mandatory to solve the problems identified above. The particular question with which this paper is concerned is what is necessary for social reporting to be an effective New Governance regulation and at the same time be politically sustainable. This paper assumes that mandatory social reporting is necessary, but it should be noted that this analysis is also applicable to understanding how to improve a voluntary system.

\section{III.A. Can We Legislate Stakeholder Engagement?}

In accordance with New Governance approaches, an important policy goal for accountability is to allow maximum stakeholder participation, which can allow context-specific solutions to emerge. As with any New Governance approach, however, power imbalances can prevent the achievement of these goals. If the parties have aligned interests, such as employers and employees focusing on worker safety in some situations, then cooperation and meaningful engagement is likely (Lobel 2004). If the interests are not aligned, which may often be the case in stakeholdercorporation negotiations, then power imbalances must be taken into account. As noted above, extant practices indicate that this power imbalance in favor of corporations has not been resolved and that reforms are necessary to directly institutionalize stakeholder participation in corporate governance.

There are various ways that stakeholders could be meaningfully involved in corporate decision making. To institutionalize such a power requires determining who should be allowed to participate, when they can participate, and how they can affect decision making. If we are only concerned with a well-defined issue facing a firm-for example, timber harvesting in a certain geographic area-then it may be possible to structure a system of stakeholder participation with meaningful input into decision making. However, even those situations face significant problems. Using the timber harvesting example, there are issues of the extent to which national environmental groups should be granted a place at the negotiation table alongside local environmental groups (Fung and Wright 2003). If numerous groups choose to be involved, how do we choose which groups get selected for participation with actual power over decision making and which groups get excluded? (Seidenfeld 2000). There also is a concern of extremist groups preventing a meaningful exchange (Gunningham, Kagan, and Thornton 2004).

The potential ways to meaningfully empower stakeholders have been studied through Ayres and Braithwaite's (1992) concept of "tripartism" (involving politically selected public interest groups given comparable power to regulatory agencies), 
experiments in negotiated agency rulemaking (Freeman 1997), and examinations of habitat conservation plans (Karkkainen, Fung, and Sabel 2000). Overall, the successful use of any of these programs may be limited to a small number of situations involving very specific, well-defined issues with ongoing relationships among the parties (Seidenfeld 2000). Stakeholder accountability through social reporting, however, seeks to cover a broad range of issues and encourage firms to alter behaviors that go beyond legal compliance. If we are considering the entire social performance of the firm, then institutionalizing stakeholder engagement with a real voice in decision making quickly moves into the realm of stakeholder representatives on the board of directors.

Although stakeholder engagement with an attempt to equalize power imbalances may be a useful regulatory measure in some situations, it is beyond the scope of social reporting. In contrast to Owen et al. 2000 and Owen, Swift, and Hunt 2001, this paper argues that social reporting can be a useful tool for stakeholder accountability even if it does not include structural reforms that institutionalize stakeholder participation in governance. If properly designed, non-financial information on corporations can empower stakeholders and form the basis for true engagement. Although certain structural reforms in corporate governance would complement social reporting, those are not necessary for social reporting to serve as a useful New Governance regulatory mechanism. The remainder of this paper will argue that the government can best support stakeholder accountability by functioning as a facilitator of dialogue, rather than constructing stakeholder engagement mechanisms through institutional reform.

\section{III.B. Making Social Reporting Mandatory: The European Experience}

Before considering the United States' experience with transparency policies, it is useful to review attempts to legislate mandatory social reports in other nations. Several countries in Europe have been experimenting with environmental or social reporting in the past several years. Between 1995 and 1999, Denmark, the Netherlands, Norway, and Sweden adopted legislation requiring certain companies to annually disclose information on their environmental performance. In 2001 (and going into force in 2002), France passed Article 116 of the Nouvelles Regulations Economiques (NRE), which requires firms to report on their environmental and social impacts (e.g., human resources, community, and labor standards). In the United Kingdom, starting in 2005, companies must include information in their annual report on their environmental and social performance "to the extent necessary" to allow shareholders to fully assess the company.

In France, firms have not had stellar compliance with NRE requirements. The deficient performance is apparently due to limited penalties for noncompliance and a failure of the NRE to provide specific standards and guidelines (Dhooge 2004). One review found that the average firm was only reporting on the most basic indicators of social performance, such as the number of employees, worker training, and employee savings plans (Entreprise Pour l'Environnement et al. 2004). The forty largest firms 
in France have a better record, but still only two-thirds reported on more than ten of forty possible social indicators and only one-third reported on more than ten of the fifty environmental indicators ${ }^{2}$ (MEDEF and PricewaterhouseCoopers 2003). In addition, only 11 percent of the reports mention that the reports were verified (either externally or internally) (MEDEF and PricewaterhouseCoopers 2003). It should be noted, however, that the number of firms reporting is a significant increase from before the law was passed, and that these firms had a very limited time frame to complete those reports after the law was passed.

In the United Kingdom, companies now must include in their annual report an "Operating and Financial Review." 3 This review should include information on the firm's environmental and social performance "to the extent necessary" for the report "to enable the members of the company to assess the strategies adopted by the company" (Department of Trade and Industry 2004: 45). The potential for Operating and Financial Reviews to work toward accountability is limited by the fact that they are directed only toward shareholders, and directors are given the discretion to determine what information is material and should be disclosed (Adams 2004; Crowe 2004; Department of Trade and Industry 2004).

Both laws appear to be fairly weak compromises and do not appear to be much, if at all, stronger than voluntary reporting initiatives. In the UK, lobbying by sizable interest groups, such as Amnesty International, Christian Aid, and Friends of the Earth, for a significantly stronger law was unsuccessful. Any legislation requiring mandatory social reporting in the United States would likely face a similar fate. However, that does not answer the question of whether this would be ineffective regulation over the long term. Enacting legislation on social reporting will be a dynamic process that can either flourish or flounder. To understand if social reporting legislation has the potential to succeed, it is necessary to look at the United States' experience with other information-based regulation.

\section{III.C. The United States' Experience with Transparency Policies}

The United States has a long history with the use of information-based policies, including financial disclosures, toxic releases, food nutrition, restaurant health grading, and many other areas. Some have been successful in meeting their regulatory goals, while others have failed. For a transparency program to work, a series of events must occur, which Fung et al. (2004) refer to as an "action cycle." The cycle begins once new information is disclosed. Next, users must take in and process the information and then alter their behavior based on the new information. Once the user has acted, then the discloser must identify those changes and respond appropriately. A new round of disclosure showing the discloser's behavior changes follows and the process starts over again (Fung et al. 2004). The success of a transparency program depends on the action cycle operating appropriately. If any links in the cycle break down-for example, the users do not change their behavior based on the disclosure of information-then the transparency program will fail. 
One area where the cycle has worked most successfully involves the laws surrounding financial disclosures. Even though current scandals have called into question the effectiveness of securities laws, overall these regulations have been highly successful in reducing risks to investors and improving corporate governance. As evidenced by the Sarbanes-Oxley Act of 2002, regulation in this area typically develops episodically in response to crises (Fung, Graham, and Weil 2002). At the start of the 1930s, financial disclosure laws were a weak compromise; some industries were excluded (e.g., railroads) and accounting standards were not standardized, which gave corporations significant discretion over how to present their financial data. Over time, though, the discovery of business practices that hid risks to investors created crises and then spurred the development of legislation that strengthened regulation. For example, the significant drop in the Dow Jones average in the early 1970s resulted in lost confidence in the market and led to the adoption of the Financial Accounting Standards Board to replace the Accounting Principles Board, which was viewed as too dominated by the accounting profession (Fung, Graham, and Weil 2002).

Fung, Graham, and Weil (2002) identify three reasons for the continuous improvement in financial disclosure regulations. First, crisis events sufficiently lowered the political power of corporations and strengthened the power of the users of information to change the laws. This is consistent with the concept of a "policy window" opening that affords advocates of reform the opportunity to push their legislation through the policy process (Kingdon 1995). Second, some disclosers were able to benefit from improved laws, such as by being able to demonstrate their strong financial status compared to competitors. Third, there were strong organizations representing the interests of users (e.g., institutional investors, stock exchanges, analysts) that could push for improvements in regulations and assist in deciphering the financial disclosures.

In contrast to financial disclosure laws, the Labor Management Reporting and Disclosure Act of 1959 (LMRDA) is an example of a transparency program that has not improved over time and has failed to meet its goals (Fung, Graham, and Weil 2002). The LMRDA was enacted to reduce the widespread corruption among union leadership at that time by providing union members with information on the financial activities and governance practices of their unions. Like the financial disclosure laws, the LMRDA started out as a weak compromise. The law required a minimal amount of information disclosure, made it difficult for union members to obtain that information, and did not require the information to be compiled in a user-friendly way (Fung, Graham, and Weil 2002). Over the next forty years the LMRDA improved very little, and union compliance with the law was often delinquent (reducing the value of the information) or incomplete.

The LMRDA did not improve from its initial form because the three factors present for the success of the financial disclosure system were absent. First, there were not sufficient crises to draw attention to the problem and open policy windows. Second, the union leadership (the disclosers) could not benefit from the disclosure 
of this information, but could only be hurt by it. Third, there was not an organized group within the unions (separate from management) that was able to collect this information, put it in a form usable to the membership, and make members aware of its value.

Fung, Graham, and Weil (2002) review a variety of other transparency regulations and conclude that the same three factors listed above are important for explaining the success or failure of those programs. Most important are the last two, which involve the ratio of benefits to costs for both the disclosers and the users of the information. The costs of disclosure come from producing the required information and any negative consequences from the disclosure of unfavorable information (e.g., lost goodwill, consumer boycotts, new regulations). Some disclosers, however, can receive benefits from disclosure, such as firms wishing to demonstrate their strong financial status compared to their competitors. If there is a subset of disclosers that have sufficiently high benefits-to-costs ratios from disclosure, then they will push for improvements in the law, or their voluntary actions will increase pressures on other disclosers to do the same.

Similarly, the benefits-to-cost ratio for users of the information also will impact the success of a transparency program. If the information is not accessible in a timely and user-friendly manner, such as with the LMRDA, then the costs will likely exceed the benefits for the user. Too much information also can increase the costs to users in some situations, since they will have difficultly sifting through the data to find the information of value. Thus, the success of transparency programs often depends on the presence of third-party intermediaries to interpret the information and pass it on to the ultimate users in an easy-to-understand format that significantly reduces the costs of use (Fung, Graham, and Weil 2002).

Technological advancements also can reduce costs. For example, recent changes to the administration of the LMRDA that take advantage of electronic dissemination over the Internet may help reduce user costs. ${ }^{4}$ However, the presence of a third party may still be necessary to help interpret the relevant information for end users. Third parties also can assist by formatting the information in a manner that allows easy comparisons between disclosers. In addition, intermediary groups are also typically important for taking advantage of policy windows by pressing policymakers for improvement and countering the political power of disclosers (Fung, Graham, and Weil 2002).

In summary, if both users and disclosers have low benefits-to-costs ratios, then we would not expect either group to use the information or exert effort in attempting to improve the system. Such a transparency program is likely to become a proforma paperwork exercise that will not develop over time. If both users and disclosers have high ratios, however, then we would expect the program to become a robust program that continues to improve over time. This does not require that all disclosers (or users) have a high ratio. Instead, once a sufficient number of disclosers or users with high ratios are present, then the program will likely become sustainable. 


\section{III.D. Toxic Release Inventory and Emissions Reductions}

One final transparency program to draw lessons from involves the effort to reduce pollution. In 1986, in response to the Union Carbide disaster in Bhopal, India (and after long-time lobbying by right-to-know groups), the United States government passed the Emergency Planning and Community Right-to-Know Act. Included in this act was the requirement commonly known as the Toxic Release Inventory (TRI), which requires companies to report their plants' emissions of certain toxic chemicals to the Environmental Protection Agency (EPA). The EPA then makes this information available to the public.

As was the case with our other examples, the TRI started out as a weak compromise. The 1986 requirements only applied to a select few industries, covered a limited number of chemicals, allowed companies to estimate their releases by various methods, did not provide for strong oversight and verification by the EPA, and did not require firms to assess the health and environmental risks of their emissions (Pedersen 2001; Fung and O'Rourke 2000). The initial response to the TRI, however, was significant. Community groups and the media publicized the information. A handful of firms even made voluntary commitments to reduce their emissions (Fung et al. 2004).

Some commentators view the TRI as one of the EPA's greatest success stories. Fung and O'Rourke state, "It is arguable that the TRI has dramatically outperformed all other EPA regulations over the last ten years in terms of overall toxics reductions and that it has done so at a fraction of the cost of those other programs" (Fung and O'Rourke 2000: 116). Between 1995 and 1998, companies in the covered industries reduced emissions of TRI pollutants by 45 percent (Fung and O'Rourke 2000). These are improvements beyond the level that firms are legally allowed to emit under environmental laws. Even though some of those may simply be "paper reductions" due to the use of loopholes (Harrison and Anweiler 2003), studies have shown a consistent decline in the listed chemicals.

The TRI has proven to be a sustainable transparency program. Over time, the TRI has increased the industries covered, significantly expanded the number of chemicals that must be reported, and has tightened reporting requirements to make them more accurate (Fung et al. 2004). The users of the data also have increased, and include all levels of government, non-governmental groups (both local and national), stock analysts, insurance companies, and consultants (EPA 2003). Homebuyers, however, have not used this information effectively (Bui and Mayer 2003).

The TRI appears to be a situation where Fung et al.'s (2004) action cycle works well. Government mandates for disclosure significantly reduced the information costs of potential users. Before government involvement, private groups were unsuccessful in pressuring firms to disclose this information and faced significant costs in collecting it themselves (Stephan 2002). With easier access to information, users were able to both have an impact in the marketplace and increase their political power (Stephan 2002). Several studies have found that the stock market reacts negatively to comparatively poor TRI reports (Badrinath and Bolster 1996; Hamilton 1995; 
Khanna, Quimio, and Bojilova 1998; Konar and Cohen 2001), and that firms with the largest stock market decline respond with greater reduction of emissions than the other firms in their industries (Konar and Cohen 1997). The reason the market reacts may be due to a perception that the information will have a negative impact on a firm's reputation and goodwill, as an indication of increased future regulation, or because poor TRI data indicate process inefficiencies or poor management (Karkkainen 2001). Overall, the reduced information asymmetries allowed citizens to engage in "informal regulation." This creates de facto regulation by increasing costs to businesses through such tactics as negative publicity, boycotts, social pressures on managers, and threats of lawsuits (Karkkainen 2001). This informal regulation also can result in new formal regulations or stricter enforcement of current laws.

In some cases, the users of the data were the companies themselves. The process of collecting the necessary information was the first time some companies had examined their discharge of chemicals and their managers were "shocked" into action (see Karkkainen 2001; EPA 2003). Some firms have even reported the information on their company Web sites to demonstrate their improvement over time and in comparison to competitors (EPA 2003; Fung et al. 2004). Thus, these disclosers were able to receive at least some benefits from disclosure.

The form of the TRI data also was important for the success of this program. The law required firms to report the pounds of chemicals emitted, which made it uncomplicated to track a firm's performance over time, to compare (and rank) different firms' performance, to look at total performance in a geographic area, and to store and distribute data (Karkkainen 2001). The ability of users to rank the relative performance of companies permitted citizen groups to use a "max-min" approach, where the "maximum" amount of pressure could be focused on the "minimum" performers (Fung and O'Rouke 2000). This results in a continual ratcheting up of the minimum standards and permits the use of different standards in different geographic areas to meet the needs of that community. In addition to comparing companies, the TRI data allow external groups to monitor a firm's performance over time, which is especially useful if a firm pledges to take certain actions and citizen groups need to monitor the firm's progress toward meeting those selfimposed goals (Karkkainen 2001). These uses are in contrast to a situation where the new information on pollution "shocks" the public into action (Stephan 2002). In response to the shock, political actors may gain motivation and power to enforce new standards, but once the information is no longer new the public loses interest and the transparency system will languish.

The presence of various intermediary groups that collected and distributed the TRI information further helped reduce costs to users and led to the program's success. For example, the citizen group Environmental Defense established the Web site scorecard.org to allow users to find the largest polluters in their community by simply searching the database by zip codes. This group and others also have improved the benefits to users by supplementing the TRI data with information that connects the pollutants and their potential health risks (EPA 2003). 
In summary, the key factors to the success of the TRI include (1) decreased user costs due to comprehensible data that allowed comparison of polluters; (2) the presence of third-party intermediaries to press for improvements in the law, to further reduce user costs by processing the information, and to increase user benefits by supplementing it with additional information; and (3) the ability of some disclosers to benefit from disclosure. These same factors led to the success of financial reporting, and their absence has caused the LMRDA to falter.

Although the simplification of the TRI data reduces user costs, it does not come without certain trade-offs. First, reductions in emissions (measured in pounds) do not directly correlate with reductions in environmental and health risks (Fung et al. 2004; Pedersen 2001; Volokh 2002). Second, the TRI data do not capture the entire picture of a firm's environmental performance, since a firm with low TRI emissions may still create environmental risks through other pollutants (Volokh 2002; Karkkainen 2001). Third, the process of collecting data and reporting them annually often means the public has data that could be too old (Cohen 2001; Karkkainen 2001). Finally, use of estimation procedures and the lack of significant verification casts some doubt on the quality of the data. Such limitations caused Fung et al. (2004) to label the TRI a "moderately effective" program: though TRI pollutants have been reduced, the overall impact on environmental and health risks is unknown.

\section{Toward a Robust Social Reporting System}

\section{IV.A. User and Discloser Benefit-to-Costs Ratios}

Any legislation mandating social reporting in the United States is likely to begin as a weak compromise. We saw this occur with social reporting legislation in France and the United Kingdom, as well as with other transparency policies in the United States. As an additional example, consider that the initial Nutrition Labeling and Education Act also started out as a compromise by, for example, excluding fast food restaurants and fresh meats from labeling requirements. These food sources not only were a significant portion of the population's diet, but also posed some of the greatest health risks to consumers (Fung, Graham, and Weil 2002). The implementation of a transparency program is a dynamic process, however. Even our long-standing financial disclosure system continues to evolve and strengthen to this date. The factors that make a transparency program effective and sustainable over the long term, such as our financial disclosure system, show that social reporting - if properly implemented — has the potential to be a robust program that works effectively toward its goal of stakeholder accountability. This section considers the prospects for social reporting to be an effective and sustainable New Governance regulatory program.

Based on the United States' experience with the transparency programs reviewed above, for social reporting to become a sustainable program that continues to improve over time, it is imperative that there be favorable benefits-to-costs ratios for both the information users and disclosers. The benefits-to-costs ratios for users and 
disclosers are often related. A high ratio for users means that in the action cycle described earlier, they will alter their behavior based on new disclosures, which may create the opportunity for some disclosers to realize a benefit from disclosure. For example, if a firm is performing better than a competitor on a certain social indicator (or can demonstrate its own improvement over time), then it may benefit through improved reputation, which, in turn, can have a positive impact in consumer markets as well as treatment in the regulatory environment. A high ratio for disclosers is necessary so that the transparency program is improved, not only through the push of users, but also from the pull of disclosers. The pull from disclosers was one of the success factors in the area of securities laws.

Increasing the benefits-to-costs ratios for both the users and disclosers depends on several factors. To improve the potential benefits to users, there must be standardized and comparable data. Standardized data is necessary to avoid problems of strategic or selective disclosure by corporations (Hess and Dunfee 2007). Comparable data allows users to punish and reward the appropriate companies, which increases benefits to users. If a user is uncertain of where a firm ranks in social performance, then the user may not act upon the information for fear of making a false-positive or false-negative assessment. In addition, if Fung and O'Rouke's (2000) "max-min" strategy applies to the social indicator, standardized and comparable data allows the continual ratcheting up of behavior, which is a key benefit of New Governance regulation over more traditional models. The idea of ratcheting is supported by limited findings that the stock market rewards companies with comparatively lower TRI emissions than industry peers, and that over time the higher-emitting firms catch up in performance to the initially lower-emitting firms (Konar and Cohen 1997; see also Konar and Cohen 2001).

In addition to providing benefits to users, standardized and comparable data also reduces costs to users. Current social reports have high user costs because they use what many refer to as a "carpet bombing" approach of providing users with numerous pages of relevant and irrelevant data. This is not to say that we should over-simplify the information to make it easier for all users to comprehend. Instead, the success of social reporting likely lies in the hands of strong third-party intermediaries. When dealing with complex data that is susceptible to misinterpretation, third-party intermediaries are essential to the functioning of the transparency program. We can refer to these groups that collect, organize, process, and disseminate the relevant information as "infomediaries" (Latham 2003).

Infomediaries played a key role in the success of securities regulations (e.g., institutional investors) and the TRI (e.g., special interest groups such as Environmental Defense and their scorecard.org Web site). Likewise, to improve information-based regulation in the provision of healthcare, Sage (1999) suggests the possibility of government-supported intermediaries to analyze disclosures and then disseminate comparative information to consumers. Some European countries have done the same for environmental information by using independent, quasi-governmental agencies to process the raw data and then distribute firm performance ratings (Co- 
hen 2001). For social reports, the necessary infomediary groups already exist and do not require additional government funding or support. These groups include socially responsible (SRI) mutual funds, public interest groups, unions, public pension funds, and the media. In addition, there is an additional layer of for-profit and non-profit infomediary groups that exist to meet the needs of the previously mentioned groups. For example, Innovest Strategic Value Advisors ${ }^{5}$ and the Investor Responsibility Research Center ${ }^{6}$ are examples of organizations that provide their clients (institutional investors, non-governmental organizations, pension funds, regulatory agencies, and corporations) with information on the environmental and social performance of individual companies and industries.

Each infomediary group serves different end users; for example, SRI mutual funds - in addition to being an end user themselves - provide information to their investors, while the media interprets social information for the general public. Although each group may have their own potential biases and propensity to misuse disclosed information to achieve their political agendas, their reputation among their end users will ultimately determine their success (see Latham 2003). In addition, with access to performance data on their competitors, corporations can themselves work to prevent the misuse of this data.

When determining the indicators to require for use in a social report, the focus should not necessarily be on the format and choice of indicators that are most accessible to all potential users, but should consider the needs of these third-party intermediaries and lowering their costs of using the information. Many current social reports appear to be written as if the general public was the audience. The Global Reporting Initiative (GRI) seems to support such an approach. Under their "clarity" principle, the GRI notes that whereas financial reporting assumes a certain level of expertise among its users, drafters of social reports should not make that assumption. Instead, the GRI states that corporations "should design reports that respond to the maximum number of users without sacrificing important details of interest to a subset of user groups" (Global Reporting Initiative 2002: 30). ${ }^{7}$ For social reporting to be sustainable and effective, however, it is these "important details of interest to a subset of user groups" that should be the primary focus of social reports. It is the role of infomediaries to process this information for other stakeholders that may not have the necessary expertise. This applies not only to the format of the report, but also to the drafting of the indicators. These indicators can-and should-be structured such that they meet the needs of the relevant infomediaries. The GRI provides some indication that it is moving in this direction by developing sector supplements to encourage firms to provide more detailed information that is relevant to their industry but not covered in the standard GRI Guidelines.

Many of these infomediary groups are also the organizations that will push for improvements in the transparency program over time. For example, CalPERS, a large public pension fund in California, has pushed for firms in the Financial Times 500 to join the Carbon Disclosure Project, has encouraged specific disclosure practices in the automobile and utilities industries, and recognizes companies for best 
practices in environmental disclosure (California State Treasurer 2005). Thus, as was the case with financial reporting, intermediary groups can ensure the long-term sustainability for social reporting and its continuous improvement.

On the discloser side, a sufficient number of firms may see benefits from expanding disclosure that they will continue to improve the process, which will support both the sustainability and effectiveness of the transparency program. For example, a recent survey of executives at major utility companies found that 63 percent of utilities (including more than 50 percent in the Americas) stated that they planned to increase environmental reporting in the future (with approximately 50 percent planning to produce a verified, standalone environmental report within the next two years [that figure was only 11 percent for North American utilities, however]). The most important reason for expanded disclosure according to the executives was the opportunity to enhance the company's brand and reputation (PricewaterhouseCoopers 2005). Likewise, other companies are able to gain the support of local communities and government regulators by demonstrating they are responsible citizens through disclosure (Cohen 2001). This is not to say that all firms will experience or seek such benefits, but that if there are a sufficient number of firms that do, then social reporting continues to develop into a sustainable program.

In addition, a system of mandatory disclosure-as opposed to a system of voluntary disclosure - can create additional opportunities for some firms to achieve benefits from disclosure. Under the current voluntary reporting system, many firms are unwilling to provide non-financial disclosures to stakeholders due to concerns that their competitors will not disclose or will only selectively disclose. This imposes costs on the disclosing firm because they may receive negative publicity from reporting negative information, even though their performance on this social indicator is above average for their industry. If there is mandatory disclosure, however, then that firm could benefit from additional disclosure, since stakeholders will be able to see their above-average performance. This can encourage the firm to push for higher standards - because all firms must then meet those standards - which helps create a sustainable transparency program. Although the reporting requirements in France and the United Kingdom are mandatory, the lack of enforcement mechanisms in France and the discretion granted to corporations in the United Kingdom makes those programs essentially voluntary and may hinder their ability to improve over time.

\section{IV.B. Effectiveness Concerns}

Creating comparable social indicators undoubtedly will raise concerns of oversimplification, resulting in indicators that are not true proxies for what they are intended to measure. This concern, however, is present in any transparency program, including financial disclosures and nutritional labeling on food packaging. The oversimplification concern is somewhat alleviated if the indicators are developed in a manner that are of use to third-party intermediaries and not the average consumer or investor, for example. As discussed above, these groups have the aptitude to 
process more complex data and make the necessary adjustments and interpretations for purposes of comparing firms, as well as the ability to determine when corporate disclosures are incomplete. The use of these intermediaries moves the social reporting format away from a general accountability to society and toward the design of indicators that are of use to key intermediary groups. The end result, however, is actually greater accountability to all stakeholder groups due to the creation of a robust transparency program.

There are other potential effectiveness concerns. A primary concern is the unintended consequences resulting from firms only managing what must be measured or taking extreme reactions on matters that must be disclosed. For example, with respect to the TRI, it is possible that firms substituted the use of listed chemicals with more environmentally hazardous methods (Pedersen 2001). Likewise, the Gap's social report (Gap, Inc. 2004) describes their response to allegations of child labor in Cambodia. In 2000, a journalist claimed he found a twelve-year-old worker (Cambodia's minimum working age is fifteen years old) in a plant that employed 3,800 people. Due to a general absence of reliable documentation of birthdates in Cambodia, the Gap's own investigation was unable to determine the child's actual age. In response, the Gap "decided to send a strong message that child labor is unacceptable and revoked approval [of the plant]. We also enhanced our age verification requirements at all remaining approved factories in Cambodia" (Gap, Inc. 2004: 24). The end result, many would argue, is not in anyone's best interest. The plant closure affected the well-being of all employees, and the stricter standards are likely to prevent many workers of legal age from securing employment at other plants due to problems of documentation. Similar situations of over-reaction occur in the environmental domain when corporations' private costs of improving their individual environmental performance on matters that must be disclosed exceed the social benefit those costs create (Cohen 2001). Misuse and over-reaction to data is a common hazard with any information-based program and can create significant challenges to their effectiveness (Sunstein 1990; see also Kahneman and Tversky 2000 on cognitive biases in interpreting information by users). This is another area, however, where key intermediary groups can process, interpret, and supplement the information to help reduce the likelihood of over-reaction. Although some groups will always attempt to distort information to induce over-reaction to achieve their own political agendas, greater access to complete information by both corporate disclosers and other intermediary groups should work to lessen the potential impact of more extremist groups.

Another potential effectiveness concern is that the approach described here places less emphasis on the disclosure of the firm's management systems and policies, and more emphasis on comparable performance indicators that can be tracked over time. Less emphasis is placed on the disclosure of policies because those policies do not ensure that performance outcomes follow. For example, the Responsible Care Initiative of American Chemistry Council (formerly known as the Chemical Manufacturers Association) is a voluntary initiative that requires its member chemi- 
cal companies to adhere to certain guiding principles and several different codes of practice. Although empirical studies on this initiative are limited, the current indications are that this program is of limited effectiveness in improving safety and environmental performance in the industry (Hess 2006). Thus, simply reporting on the presence of policies or codes of practice does not ensure that regulatory performance objectives are being met.

Reporting on the presence of management systems and policies is still important for several reasons, however. First, annual performance indicators focus on current, short-term results, whereas stakeholders still need assurance that management has systems in place to anticipate and prevent potential long-term problems. Second, these systems are essential for a reflexive law approach that seeks to influence the decision-making process of the organization (Hess 1999, 2001). The ultimate goal of a reflexive law-and New Governance-approach is to ensure that corporations are meaningfully thinking "critically, creatively, and continually" about their social performance and how to improve it (Orts 1995b: 780). As discussed above, current practices suggest that, for the vast majority of firms, social reporting is not being used in this manner but instead for stakeholder management. This suggests that the best way to achieve our regulatory goals in this area-at least initially-is not by the assurance of certain policies in place but by providing stakeholders with actual power through information. Only through true accountability to stakeholders will corporations engage in the necessary self-reflection and organizational learning.

Overall, where performance outcome indicators are not available or are overly costly to develop, then reporting on policies is the best we can hope for (Coglianese and Lazer 2003) and should be a part of any mandatory disclosure regulation. Though such information may not be easily reported or analyzed if presented in a manner suitable to all readers, if directed toward the needs of the appropriate infomediaries, then these indicators may be useful. For example, private ratings organizations, such as Innovest, do use this information to predict firms' future performance (Cohen 2001).

\section{Conclusion}

Corporate social reporting has the potential to become a successful and effective form of New Governance regulation. Rather than operating from a command-andcontrol basis, the goal of New Governance regulation is to encourage participation by stakeholders and allow location or issue-specific solutions to emerge and evolve over time as society changes. Social reporting facilitates this by reducing the costs of meaningful participation by all interested stakeholder groups and increases the likelihood of actual engagement with the firm. Arguing from an empowered position due to greater access to information, stakeholders can demand real change from corporations and work with them to find mutually agreeable solutions. For example, in their study of stakeholders' impact on the environmental performance of paper mills, Gunningham, Kagan, and Thornton (2004: 328-29) conclude: "We 
found it more useful to think not only of social pressures, but also of regulatory and economic pressures, as terms or conditions of a multifaceted 'license to operate.' ... The relationship between the licensors and licensees is interactive, not unidirectional, and many of the license terms are open to interpretation, negotiation, and company-initiated amendment." These pressures to change the "license terms" may operate on many different levels, including, for example, a firm's national reputation, pressure on local managers, or pressure on boards of directors' social networks (see Cohen 2001). Important infomediary groups, with information collected from social reports, assist this process by getting the right information to the right groups at the right time.

To achieve the goals of New Governance regulation, the foundation of social reports should be information, not the establishment of stakeholder engagement processes. To function as a bottom-up, participatory and experimental regulatory measure, social reporting must have top-down mandates for disclosure. This grants stakeholders negotiating power and allows true collaborate governance to develop around particular firms and issues. To have meaningful stakeholder engagement requires that we first have a robust information-based transparency policy with comparable data. Comparable data is necessary to allow users to focus on the worst performers to ratchet up minimum standards and also allows some disclosers to benefit as top performers.

We do not need to wait until the social reporting process is more mature before mandating the use of standardized indicators for social reports. It is important to remember that the adoption of any transparency policy program is a dynamic process. The initial round of legislation will fall well short of the ideals of social reporting advocates. However, based on past United States experience with transparency programs, if the selection of indicators allows high benefits-to-costs ratios for a sufficient number of users and disclosers, then it can develop into a robust program. Over time, lowering the costs to users, such as consumers and investors, will make this information more valuable to some disclosers and give them incentives to pay more attention to it. If this information is not widely used, however, then firms have little incentive to invest in improving the system.

Of primary importance is ensuring that those indicators meet the needs of thirdparty intermediaries, which can help improve the benefits-to-costs ratios of both users and disclosures of social and environmental information. Such a mandatory system does not need to be a complete substitute for voluntary initiatives, such as the Global Reporting Initiative, but they can be mutually reinforcing. The required disclosure of certain information will push firms to attempt to explain and justify their actions to regain legitimacy, which may result in their adoption of broader social reports.

The approach to social reporting described here is a pragmatic approach to focusing on what works and building upon that foundation (Karkkainen 2001). We do not need perfect information on a corporation's social performance, but we do need information sufficient to allow the meaningful involvement of stakeholders. 
Many social reporting advocates seem to be working toward an ideal of stakeholder dialogue. Without counter-balancing power, however, this is unlikely to lead to stakeholder accountability and significant behavioral changes by corporations. It may even result in the action cycle working in reverse, where the discloser creates the perceptions that drive changes in the user's behavior. Instead, the goal is to close the loop of the action cycle and ensure there is a connection between disclosure of social information and change in corporate behavior.

\section{Notes}

1. We can view regulatory approaches as existing on a continuum, with pure self-regulation on one end (e.g., industry developing and enforcing its own standards of conduct (Gunningham and Rees 1997)) and command-and-control regulation on the other (i.e., strict standards established by a centralized body) (Sinclair 1997).

2. These indicators are not specifically part of the NRE, but were apparently derived from the NRE by MEDEF and PricewaterhouseCoopers.

3. Since the drafting of this manuscript, the UK government abruptly cancelled the Operating and Financial Review (OFR) requirement and then after protests subsequently adopted a similar (but less rigorous) standard referred to as a "business review." Many UK companies, however, have vowed to publish OFR reports on a voluntary basis.

4. See the Department of Labor Web site on the LMRDA, at http://www.dol.gov/dol/ compliance/comp-lmrda.htm.

5. See Innovest Strategic Value Advisor's Web page at www.innovest.com.

6. See Investor Responsibility Research Center's Web page at www.irrc.org.

7. In the time since the drafting of this manuscript, the GRI has released an updated version of their guidelines. In describing the clarity principle, the new guidelines state that "Information should be presented in a manner that is comprehensible to stakeholders who have a reasonable understanding of the organization and its activities" (Global Reporting Initiative 2006: 16). The guidelines do not define "reasonable understanding," but we can assume that it is a low threshold as the guidelines also state that the "report should present information in a way that is understandable, accessible, and usable by the organization's range of stakeholders" (Global Reporting Initiative 2006: 16).

\section{References}

Aalders, Marius, and Tom Wilthagen. 1997. "Moving Beyond Command and Control: Reflexivity in the Regulation of Occupational Safety and Health and the Environment," Law and Policy 19(4): 415-43.

Adams, Carol A. 2004. "The Ethical, Social and Environmental Reporting Performance Portrayal Gap," Accounting, Auditing and Accountability Journal. 17: 731-57. Ayres, Ian, and John Braithwaite. 1992. Responsive Regulation: Transcending the Deregulation Debate. New York: Oxford University Press.

Badrinath, Swaminathan G., and Paul J. Bolster. 1996. "The Role of Market Forces in EPA Enforcement Activity," Journal of Regulatory Economics 10(2):165-81. 
Ball, Amanda, David Owen, and Rob Gray. 2000. "External Transparency or Internal Capture? The Role of Third-Party Statements in Adding Value to Corporate Environmental Reports." Business Strategy and the Environment 9(1): 1-23.

Berthelot, Sylvie, Denis Cormier, and Michel Magnan. 2003. "Environmental Disclosure Research: Review and Synthesis," Journal of Accounting Literature 22(1): 1-44.

Bui, Linda T., and Christopher J. Mayer. 2003. "Regulation and Capitalization of Environmental Amenities: Evidence from the Toxics Release Inventory in Massachusetts," Review of Economics and Statistics 85(3): 693-708.

California State Treasurer. 2005. "CalPERS Approves Final Piece of Angelides' 'Green Wave' Environmental Investment Initiative to Reduce Fund's Risk by Improving Corporate Environmental Practices." California State Treasurer Phil Angelides News Release, February 15, 2005 (available online at www.treasurer.ca.gov).

Coglianese, Cary, and David Lazer. 2003. "Management-Based Regulation: Prescribing Private Management to Achieve Public Goals." Law and Society Review 37(4): 691-730.

Cohen, Mark A. 2001. "Information as a Policy Instrument in Protecting the Environment: What Have We Learned?" Environmental Law Reporter 31(10): 425-31.

Crowe, Roger. 2004. "Transparency Issue Can Be Easily Clouded.” Financial Times (November 29): 6.

Cumming, Jane Fiona. 2001. "Engaging Stakeholders in Corporate Accountability Programmes: A Cross-Sectoral Analysis of UK and Transnational Experience," Business Ethics: A European Review 10: 45-52.

Deegan, Craig. 2002. "The Legitimising Effect of Social and Environmental Disclosures: A Theoretical Foundation." Accounting, Auditing \& Accountability Journal 15(3): 282-311.

Deegan, Craig, and Michaela Rankin. 1996. "Do Australian Companies Report Environmental News Objectively? An Analysis of Environmental Disclosures by Firms Prosecuted Successfully by the Environmental Protection Authority," Accounting, Auditing \& Accountability Journal 9(2): 50.

Deegan, Craig, Michaela Rankin, and John Tobin. 2002. "An Examination of the Corporate Social and Environmental Disclosures of BHP from 1983-1997," Accounting, Auditing \& Accountability Journal 15(3): 312-43.

Deegan, Craig, Michaela Rankin, and Peter Voght. 2000. "Firms' Disclosure Reactions to Major Social Incidents: Australian Evidence," Accounting Forum 24(10): 101-31.

Department of Trade and Industry. 2004. "Draft Regulations on the Operating and Financial Review and Directors' Report A Consultative Document" (May). Available online at: http://www.dti.gov.uk.

Dhooge, Lucien J. 2004. "Beyond Voluntarism: Social Disclosure and France's Nouvelles Regulations Economiques." Arizona Journal of International and Comparative Law 21: 441-91.

Dorf, Michael C., and Charles F. Sabel. 1998. "A Constitution of Democratic Experimentalism," Columbia Law Review 98: 267.

Entreprise Pour l'Environnement, Entreprise et Collectivités Partenaires pour l'Environnement, and Observatoire sur la Responsabilité Sociétale des Entreprises. 2004. "Critical Review of How Companies are Applying French Legislation on 
Social and Environmental Reporting." Available online at http://www.orse.org/gb/ home/publications.html.

Environmental Protection Agency (EPA). 2003. "How Are the Toxic Release Inventory Data Used?: Government, Business, Academic, and Citizen Uses.” Toxics Release Inventory Program Division, Office of Environmental Information, U.S. Environmental Protection Agency, EPA-260-R-002-004, May 2003.

Freeman, Jody. 1997. "Collaborative Governance in the Administrative State." UCLA Law Review 45: 1.

Fung, A., and D. O'Rourke. 2000. "Reinventing Environmental Regulation from the Grassroots Up: Explaining and Expanding the Success of the Toxics Release Inventory." Environmental Management 25: 115-27.

Fung, Archon, Mary Graham, and David Weil. 2002. "The Political Economy of Transparency: What Makes Disclosure Policies Sustainable?’ Harvard University, Institute for Government Innovation, Working Paper \# OPS-02-03, 2002.

Fung, Archon, David Weil, Mary Graham, and Elena Fagotto. 2004. "The Political Economy of Transparency: What Makes Disclosure Effective?" Harvard University, Ash Institute for Democratic Governance and Innovation, Working Paper \# OP-03-04.

Fung, Archon, and Erik Olin Wright, eds. 2003. Deepening Democracy: Institutional Innovations in Empowered Participatory Governance. New York: Verso.

Gap, Inc. 2004. "2003 Social Responsibility Report.” Available online at http://www .gapinc.com/social_resp/social_resp.htm.

Garrett, Brandon L, and James S. Liebman. 2004. "Experimentalist Equal Protection.” Yale Law \& Policy Review 22: 261-327.

Global Reporting Initiative. 2002. Sustainability Reporting Guidelines. 2006. Sustainability Reporting Guidelines.

Gray, Rob. 2001. "Thirty Years of Social Accounting, Reporting and Auditing: What (If Anything) Have We learned?" Business Ethics: A European Review 10: 9-15.

Gunningham, Neil, Robert A. Kagan, and Dorothy Thornton. 2004. "Social License and Environmental Protection: Why Businesses Go Beyond Compliance." Law \& Social Inquiry 29: 307.

Gunningham, Neil, and Joseph Rees. 1997. "Industry Self-Regulation: An Institutional Perspective." Law and Policy 19(4): 363-414.

Hamilton, James. 1995. "Pollution as News: Media and Stock Market Reactions to the Toxics Release Inventory Data.” Journal of Environmental Economics and Management 28: 98-113.

Harrison, Kathyrn, and Werner Anweiler. 2003. "Incentives for Pollution Abatement: Regulation, Regulatory Threats, and Non-Governmental Pressures." Journal of Policy Analysis and Management 22(3): 361-82.

Hess, David. 1999. "Social Reporting: A Reflexive Law Approach to Corporate Social Responsiveness." Journal of Corporation Law 25(1): 41-84.

Hess, David. 2001. "Regulating Corporate Social Performance: A New Look at Corporate Social Accounting, Auditing and Reporting." Business Ethics Quarterly 11(2): 307-30. 
Hess, David. 2006. "Corporate Social Responsibility and the Law," in Corporate Social Responsibility, ed. José Allouche. Hampshire, UK: Palgrave Macmillan, 154-80.

Hess, David, and Thomas W. Dunfee. 2007. "The Kasky-Nike Threat to Corporate Social Reporting: Implementing a Standard of Optimal Truthful Disclosure as a Solution?” Business Ethics Quarterly 17(1) (January 2007): 5-32.

Hooghiemstra, Reggy. 2000. "Corporate Communication and Impression Management: New Perspectives Why Companies Engage in Social Reporting." Journal of Business Ethics 27(1/2): 55-68.

Kahneman, Daniel, and Amos Tversky, eds. 2000. Choices, Values, and Frames. New York: Russell Sage Foundation.

Karkkainen, Bradley C. 2001. "Information as Environmental Regulation: TRI and Performance Benchmarking, Precursor to a New Paradigm?" Georgetown Law Journal 89: 257-370.

2004. "New Governance' in Legal Thought and in the World: Some Splitting as Antidote to Overzealous Lumping." Minnesota Law Review 89: 471.

Karkkainen, Bradley, Archon Fung, and Charles Sabel. 2000. "After Backyard Environmentalism: Toward a Performance-Based Regime of Environmental Regulation." American Behavioral Scientist 44(4): 692-711.

Khanna, Madhu, Rose H. Quimio, and Dora Bojilova. 1998. "Toxic Release Information: A Policy Tool for Environmental Protection." Journal of Environmental Economics and Management, 36: 243-66.

Kingdon, John W. 1995. Agendas, Alternatives and Public Policies, 2nd ed. Boston: Addison-Wesley.

Konar, Shameek, and Mark A. Cohen. 1997. "Information as Regulation: The Effect of Community Right to Know Laws on Toxic Emissions." Journal of Environmental Economics and Management. 32(1): 109-24.

2001. "Does the Market Value Environmental Performance?" Review of Economics and Statistics, 83(2): 281-302.

Latham, Mark. 2003. "Democracy and Infomediaries." Corporate Governance: An International Review 11(2): 91-101.

Laufer, William S. 1999. "Corporate Liability, Risk Shifting, and the Paradox of Compliance.” Vanderbilt Law Review 54: 1343-97.

Lobel, Orly. 2004. "The Renew Deal: The Fall of Regulation and the Rise of Governance in Contemporary Legal Thought." Minnesota Law Review 89: 342.

Malloy, Timothy F. 2003. "Regulation, Compliance, and the Firm." Temple Law Review 76: 451-531.

May, Peter J. 2004. "Compliance Motivations: Affirmative and Negative Bases." Law and Society Review 38(1): 41-68.

MEDEF and PricewaterhouseCoopers. 2003. Prise en compte de l'article 116 de la Loi NRE dans le rapport de gestion des entreprises du CAC 40. Available online at www.pwcglobal.com/fr/pwc_pdf/pwc_loi_nre.pdf.

O'Donovan, Gary. 2002. "Environmental Disclosures in the Annual Report: Extending the Applicability and Predictive Power of Legitimacy Theory." Accounting, Auditing \& Accountability Journal 15(3): 344-72. 
Orts, Eric W. 1995a. "Reflexive Environmental Law." Northwestern University Law Review 89: 1227-1340.

1995b. "A Reflexive Model of Environmental Regulation." Business Ethics Quarterly 5: 779.

Owen, David L., Tracey Swift, Christopher Humphrey, and Mary Bowerman. 2000. "The New Social Audits: Accountability, Managerial Capture or the Agenda of Social Champions?" European Accounting Review 9(1): 81-99.

Owen, David L., Tracy Swift, and Karen Hunt. 2001. "Questioning the Role of Stakeholder Engagement in Social and Ethical Accounting, Auditing, and Reporting." Accounting Forum 25(3): 264-82.

Parker, Christine. 2002. The Open Corporation: Effective Self-Regulation and Democracy. Cambridge: Cambridge University Press.

Pedersen, William F. 2001. "Regulation and Information Disclosure: Parallel Universes and Beyond." Harvard Environmental Law Review 25: 151.

PricewaterhouseCoopers. 2005. Under Pressure: Utilities Global Survey 2005. Available online at www.pwc.com/energy.

Rogowski, Ralf, and Ton Wilthagen, eds. 1994. Reflexive Labour Law: Studies in Industrial Relations and Employment Regulation. London: Kluwer Law International.

Ruhnka, John C., and Heidi Boerstler. 1998. "Governmental Incentives for Corporate Self-Regulation.” Journal of Business Ethics 17(3): 309-37.

Sage, William M. 1999. "Regulating through Information: Disclosure Laws and American Health Care.” Columbia Law Review 99: 1701-1829.

Seidenfeld, Mark. 2000. "Empowering Stakeholders: Limits on Collaboration as the Basis for Flexible Regulation.” William and Mary Law Review 41: 411-501.

Sinclair, Darren. 1997. "Self-Regulation versus Command and Control? Beyond False Dichotomies." Law and Policy 19(4): 529-59.

Stephan, Mark. 2002. "Environmental Information Disclosure Programs: They Work, But Why?" Social Science Quarterly 83(1): 190-205.

Sturm, Susan. 2001. "Second Generation Employment Discrimination: A Structural Approach.” Columbia Law Review 101: 458.

Sunstein, Cass R. 1990. "Paradoxes of Regulatory State." University of Chicago Law School 57: 407-41.

Swift, Tracy. 2001. "Trust, Reputation and Corporate Accountability to Stakeholders." Business Ethics: A European Review 10(1): 16-26.

Volokh, Alexander. 2002. "The Pitfalls of the Environmental Right-to-Know." Utah Law Review 2: 805.

Walden, W. Darrell, and Bill N. Schwartz. 1997. "Environmental Disclosures and Public Policy Pressure." Journal of Accounting and Public Policy 16(2): 115-244. 